\section{Editorial}

Gabriele Rippl und Michael Stolz

\section{UniBern Forschungsstiftung}

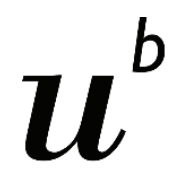

b

UNIVERSITÄT

BER N

Walter Benjamin Kolleg

\title{
Original und Kopie: Techniken und Ästhetiken der re-/produktiven Abweichung
}


Das vorliegende Heft der Kulturwissenschaftlichen Zeitschrift mit dem Titel "Original und Kopie: Techniken und Ästhetiken der re-/produktiven Abweichung" bildet Ergebnisse einer gleichnamigen internationalen und interdisziplinären Tagung ab, die im Dezember 2016 an der Universität Bern stattfand, und reflektiert mehrjährige Diskussionen der Forschungsplattform "Original und Kopie - Techniken und Ästhetiken der Reproduzierbarkeit" des Walter Benjamin-Kollegs an der Philosophisch-historischen Fakultät der Universität Bern. An den interdisziplinären Gesprächen teilgenommen haben neben Kolleginnen und Kollegen aus den geistes- und kulturwissenschaftlichen Fächern der Literatur-, Kunst- und Tanzwissenschaft auch Vertreterinnen und Vertreter aus der Rechtswissenschaft, der Medien- und Sprachwissenschaft sowie der Molekularbiologie. Ihnen allen gilt unser großer Dank für die Bereitschaft zum disziplinenübergreifenden Dialog, der äußerst anregend war.

Die Mitglieder der Forschungsplattform Christine Göttler (Kunstwissenschaft der Frühen Neuzeit), Gabriele Rippl (Literaturwissenschaft
/ Anglistik / Amerikanistik; Sprecherin der Forschungsplattform), Peter J. Schneemann (Kunstwissenschaft der Gegenwart), Michael Stolz (Literaturwissenschaft / germanistische Mediävistik) und Christina Thurner (Tanzwissenschaft) danken dem Walter Benjamin-Kolleg und der Philosophisch-historischen Fakultät der Universität Bern für die mehrjährige Unterstützung.

Dieses Heft hätte nicht ohne die grosszügige finanzielle Unterstützung des Walter Benjamin-Kollegs, der Philosophisch-historischen Fakultät der Universität Bern und die generöse Mitfinanzierung der UniBern Forschungsstiftung publiziert werden können. Diesen Institutionen gilt unser besonderer Dank.

Wir danken ausserdem Prof. Dr. Liebert und dem Herausgebergremium der Kulturwissenschaftlichen Zeitschrift sowie Leyla Dörflinger vom De Gruyter Verlag für die unermüdliche Unterstützung und kompetente Begleitung des Publikationsprozesses. Dank gilt auch unserem Team, namentlich Michael Boog, Elena Brandazza und Jasmin Lal. 